\title{
Reproductive parameters of dairy goats after receiving two doses of d-cloprostenol at different intervals
}

\author{
A.L.R.S. Maia ${ }^{a}$, F.Z. Brandão ${ }^{a}$, J.M.G. Souza-Fabjan ${ }^{\mathrm{a}, \mathrm{b}}$, M.F.A. Balaro ${ }^{\mathrm{a}}$, \\ M.E.F. Oliveira ${ }^{c}$, O. Facód ${ }^{\mathrm{d}}$, J.F. Fonseca ${ }^{\mathrm{d}, *}$ \\ a Faculty of Veterinary Medicine, Fluminense Federal University, Av. Vital Brasil Filho, 64, CEP 24230-340, Niterói, RJ, Brazil \\ b Faculty of Veterinary Medicine, School of Health Sciences, Universidade do Grande Rio, Rua Prof. José de Souza Herdy, 1160, CEP 25071-202, \\ Duque de Caxias, RJ, Brazil \\ c College of Agricultural and Veterinary Sciences, São Paulo State University, Access by Prof. Paulo Donato Castellane, s/n, CEP 14.884-900, \\ Jaboticabal, SP, Brazil \\ d Embrapa Goats and Sheep Research Center, Estrada Sobral/Groaíras, km 04, CP 145, CEP 62010-970, Sobral, CE, Brazil
}

\section{A R T I C L E I N F O}

\section{Keywords:}

AI

Caprine

PGF2 $\alpha$ analog

Prostaglandin

Reproductive performance

\begin{abstract}
A B S T R A C T
This study evaluated the efficiency of two d-cloprostenol injections at different intervals on the reproductive parameters of dairy goats. Trial 1 comprised 54 goats allocated to receive two $37.5 \mu \mathrm{g}$ d-cloprostenol doses at intervals of seven $\left(\mathrm{T}_{7}, \mathrm{n}=19\right), 10\left(\mathrm{~T}_{10}, \mathrm{n}=18\right)$, and $11.5\left(\mathrm{~T}_{11.5}\right.$, $\mathrm{n}=17)$ days. Trial 2 comprised 62 goats allocated to receive injections at $\mathrm{T}_{7}(\mathrm{n}=30)$ and $\mathrm{T}_{11.5}$ $(\mathrm{n}=32$ ). Ultrasonography was done and blood was collected just before d-cloprostenol injections. After the second dose, goats were artificially inseminated (AI) with frozen-thawed semen at 18-24 h (Trial 1) or at 10-24 h (adjusted according to the time of estrus onset in Trial 2) after estrus detection. Estrus response rate did not differ $(\mathrm{P}>0.05)$ among groups in Trials 1 $\left(\mathrm{T}_{7}=94.7 \% ; \mathrm{T}_{10}=88.9 \% ; \mathrm{T}_{11.5}=88.2 \%\right)$ and $2\left(\mathrm{~T}_{7}=90.0 \% ; \mathrm{T}_{11.5}=96.9\right)$. All females showed progesterone concentrations $>1 \mathrm{ng} / \mathrm{mL}$ before both d-cloprostenol injections. The largest follicle diameter present on ovaries was similar $(\mathrm{P}>0.05)$ among treatments at the first and second dose. The second largest follicle diameter was superior $(P<0.05)$ to $T_{7}$ than to $T_{10}$ and $T_{11.5}$ goats at first dose only. This possibly resulted in lower interval to estrus $(\mathrm{P}<0.05)$ in $\mathrm{T}_{7}$-treated goats than other treated goats in both trials. The conception rate was similar among treatment groups in Trials $1 \quad\left(\mathrm{~T}_{7}=55.6 \% ; \quad \mathrm{T}_{10}=18.8 \% ; \quad \mathrm{T}_{11.5}=26.7 \%\right)$ and $2 \quad\left(\mathrm{~T}_{7}=85.2 \%\right.$; $\mathrm{T}_{11.5}=93.6 \%$ ). The three treatments efficiently synchronized estrus. $\mathrm{T}_{7}$ and $\mathrm{T}_{11.5}$ protocols resulted in high estrus synchrony and conception rates when adjusting the AI time according to interval of estrus.
\end{abstract}

\section{Introduction}

Estrus synchronization may be applied to facilitate reproductive management, enabling the farmer to organize the production system (Vázquez et al., 2010). In some countries, there are restrictive issues on the use of progestins and gonadotropins due to concerns for public health and animal welfare. Therefore, the search for feasible alternatives became essential. Artificial insemination (AI) can lead to important genetic improvements for dairy goat production (Menchaca and Rubianes, 2004; Vázquez et al., 2010). Thus, during the breeding season, when females are cyclic, the possibility of achieving estrus synchronization only by the use of

\footnotetext{
* Corresponding author.

E-mail address: jeferson.fonseca@embrapa.br (J.F. Fonseca).
} 
prostaglandin $\mathrm{F} 2$ alfa analogues (PGF2 $\alpha$ ) becomes an attractive choice, specially when reproductive seasonality is not evident or shorter than in higher latitudes. These drugs can potentially reduce costs and do not present complications as have been reported in other protocols, such as the production of antibodies (Baril et al., 1996), the development of ovarian diseases, such as follicular cysts (Santiago Moreno et al., 1999) or vaginitis (Penna et al., 2013).

Several studies in our group have recommended the use of two doses of d-cloprostenol (PGF2 $\alpha$ ) at 10-day intervals (Siqueira et al., 2009; Fonseca et al., 2012; Esteves et al., 2013). However, this protocol does not always achieve the expected success due to the possible occurrence of a short estrus cycle, a reasonably common phenomenon in goats (Camp et al., 1983; Chemineau et al., 2006; Holtz et al., 2008). It is possible that reducing the interval between both PGF2 $\alpha$ administrations to seven days would be one method of overcoming this problem. Menchaca et al. (2004) have reported good results using two doses of PGF2 $\alpha$ analog (delprostenate) at seven-day intervals for estrus synchronization in sheep. Thus, the corpus luteum (CL) formed after the first administration of PGF2 $\alpha$ is responsive to luteolytic activity at the second dose, even if this CL has an impaired luteal function. It should be confirmed in goats. Another alternative is to increase the interval time to 11.5 days. This time enables the development of a new follicular wave after the first dose, as well as the luteolysis in the middle or at the start of the luteal phase in case of premature regression of the CL. In addition, the protocol of 11.5 days would allow the second PGF2a to be administered at the end of afternoon, since the estrus onset is possibly associated with night events (Fonseca et al., 2005).

Our current hypothesis is that the occurrence of short estrus cycles in goats may adversely affect estrus synchronization after two doses of PGF2 $\alpha$ at 10-day intervals. Therefore, this study was carried out to compare different intervals (7, 10, or 11.5 days) of two cloprostenol administration on estrus synchronization and fertility after $\mathrm{AI}$ in dairy goats raised under tropical conditions during the breeding season.

\section{Material and methods}

\subsection{Ethics and experimental conditions}

This study was approved by the Animal Care Committee of Fluminense Federal University (protocol number 116/11), and it was conducted under the principles of Brazilian Society of Laboratory Animal Science. The experiment was carried out from March to May, during the breeding season in Coronel Pacheco $\left(21^{\circ} 35^{\prime} \mathrm{S}\right.$ and $\left.43^{\circ} 15^{\prime} \mathrm{W}\right)$, Minas Gerais, Brazil. All goats were kept in an intensive system and fed with corn silage, chopped Pennisetum purpureum, and Cynodon spp. hay. A balanced concentrate supplement was given according to their demand (National Research Council, 2007), as well as mineralized salt (Caprinofós ${ }^{\circledR}$ Tortuga, São Paulo, Brazil), and drinking water was available ad libitum.

\subsection{Experimental animals and treatments}

Two trials were conducted. Trial 1 tested three different intervals of cloprostenol administration. Protocols resulting in good estrus response and synchrony and expected good pregnancy in Trial 1 were test in Trial 2, adjusting the timing of AI according to the interval to estrus onset of goats.

\subsubsection{Trial 1}

A total of 54 (31 nulliparous and 23 pluriparous) cyclic Saanen goats averaging $49.8 \pm 16.3 \mathrm{~kg}$ of body weight (BW) and $3.0 \pm 0.4$ of body condition score (BCS, 1-5 range; Detweiler et al., 2008) were used and equally allocated into three treatments according to their category (nulliparous or pluriparous), BW and BCS. For estrus synchronization, two doses of $37.5 \mu \mathrm{d}$-cloprostenol (Prolise ${ }^{\oplus}$, Tecnopec LTDA, São Paulo, Brazil) were given through the laterovulvar route at intervals of 7 days $\left(\mathrm{T}_{7}\right.$; $\mathrm{n}=19$ ), 10 days $\left(\mathrm{T}_{10} ; \mathrm{n}=18\right)$, or 11.5 days $\left(\mathrm{T}_{11.5}, \mathrm{n}=17\right)$. Because of main parameters are related to the second cloprostenol dose, the study was designed so that the second d-cloprostenol injection was performed on the same day for all goats. $\mathrm{T}_{7}$ and $\mathrm{T}_{10}$ goats received $\mathrm{d}$ cloprostenol administrations at 06:00-07:00 a.m., while $\mathrm{T}_{11.5}$ goats received the first and second dose of d-cloprostenol at 06:00-07:00 am and 05:00-06:00 pm, respectively.

\subsubsection{Trial 2}

A total of 62 cyclic pluriparous goats (40 Alpine and 22 Saanen) with $3.2 \pm 0.3$ of BCS were equally assigned according to BCS and breed to two treatments. For estrus synchronization, two doses of $37.5 \mu \mathrm{g}$ d-cloprostenol were given through the laterovulvar route at intervals of 7 days $\left(T_{7} ; n=30\right)$ and 11.5 days $\left(T_{11.5} ; n=32\right)$. As performed in Trial 1 , the second d-cloprostenol injection was administered in morning $\left(\mathrm{T}_{7}\right)$ and in the afternoon $\left(\mathrm{T}_{11.5}\right)$ of the same day for all goats.

\subsection{Blood sample collection and assays}

Blood samples were collected from each animal of Trial 1, just before each d-cloprostenol injection, by jugular venipuncture into heparinized tubes. Plasma was immediately separated by centrifugation at $1500 \mathrm{~g}$ for 15 min and stored at $-20^{\circ} \mathrm{C}$ for hormonal assay. The measurement of plasma progesterone concentration was performed by solid-phase radioimmunoassay kits (Beckman Coulter; Immunotech, Marseille, France) at the Hormonal Dosage Laboratory, Animal Reproduction Unit, Fluminense Federal University. The assay sensitivity and intra-assay coefficients of variation were $0.05 \mathrm{ng} / \mathrm{mL}$ and $12 \%$. In addition, all data were within the maximum and minimum points of the curve. 


\subsection{Ovarian ultrasonography}

Transrectal ovarian ultrasonography was performed (by the same operator) just before each d-cloprostenol injection in all goats of Trial 1. The examinations were conducted with a B-mode transrectal ultrasonographic scanner (KX2000G Vet ${ }^{\circledR}$, Kaixin, Xuzhou, China) with a 7.5 MHz transducer fitted to a plastic rod that allowed the transrectal manipulation of the probe. Does were maintained in a standing position, fecal pellets were removed manually, and 10-20 mL of carboxymethylcellulose gel was placed into the rectum with a syringe. Ovaries were located and follicles $\geq 2 \mathrm{~mm}$ were measured and recorded.

\subsection{Estrus detection and artificial insemination (AI)}

In both trials, $12 \mathrm{~h}$ after each d-cloprostenol injection, estrus was monitored using fertile bucks twice a day (06:00-08:00 am and 4:00-6:00 pm). Females were considered to be in estrus when they allowed to be mounted by teaser bucks. The end of estrus was consideredwhen does no longer accepted to be mounted.

After the second dose, does displaying signs of estrus were AI as earlier described (Fonseca et al., 2011), using commercial frozen/ thawed semen. Briefly, does were maintained at standing position, a Collin speculum was inserted into vagina, cervix was located and immobilized by means of Allis forceps and semen applicator was introduced through the cervix to access uterine body. Uterine insemination was considered to be performed when total loss of resistance was reached. The maximal time elapsed from cervical immobilization and semen deposition was $1 \mathrm{~min}$. In Trial 1, the procedure was applied from $18 \mathrm{~h}$ (goats starting estrus late in the afternoon) to $24 \mathrm{~h}$ (goats starting estrus early in the morning) after estrus detection.

In Trial 2, AI was adjusted according to the interval to estrus onset of females. AI was performed after $24 \mathrm{~h}$ and $18 \mathrm{~h}$ for $\mathrm{T}_{7}$ goats such as Trail 1. For $\mathrm{T}_{11.5}$ goats, AI was performed $24 \mathrm{~h}, 18 \mathrm{~h}$ and $10 \mathrm{~h}$ for goats with interval to estrus $36 \mathrm{~h}, 48 \mathrm{~h}$ and $60 \mathrm{~h}$ after the second cloprostenol administration, respectively.

\subsection{Conception rate}

Approximately 60 days after AI, the conception rate was diagnosed by a B-mode transrectal ultrasonographic scanner (KX2000G Vet ${ }^{\oplus}$, Kaixin, Xuzhou, China) with a multifrequential (4.5-7.5 MHz) transducer adapted with a plastic rigid tube for use in small ruminants. At that time, viable gestation and hydrometra were well differentiated.

\subsection{Statistical analysis}

For statistical analysis, SAEG ${ }^{\bullet} 9.0$ software (UFV, Minas Gerais, Brazil) was used. Descriptive statistics for the reproductive and hormonal data were calculated. The Lilliefors test was used to verify the data normality. Parametric data were analyzed using a mixed model procedure for repeated measures, and the Tukey's test was used to compare the means. Nonparametric data were assessed by the Fisher's exact test. Pearson correlations were performed among variables (Ribeiro Júnior, 2001). The significance level adopted for all analyses was $5 \%$.

\section{Results}

\subsection{Trial 1}

All goats showed plasma progesterone concentrations $>1 \mathrm{ng} / \mathrm{mL}$ immediately before the administration of the first and second dose of d-cloprostenol. Reproductive parameters are listed in Table 1. A negative correlation $(\mathrm{r}=-0.40$; $\mathrm{P}<0.01)$ was found between the interval to estrus onset and the duration of estrus.

Estrus related to the first d-cloprostenol administration was grouped regardless of the treatment, and the data related to the

Table 1

Reproductive parameters of cyclic Saanen goats after estrus synchronization with two injections of $30 \mu \mathrm{d}$-cloprostenol at 7,10 , and 11.5 days apart (Mean \pm SD).

\begin{tabular}{|c|c|c|c|c|c|c|}
\hline \multirow[t]{3}{*}{ Parameter } & \multicolumn{2}{|l|}{$\mathrm{T}_{7 \text { days }}$} & \multicolumn{2}{|l|}{$\mathrm{T}_{10 \text { days }}$} & \multicolumn{2}{|l|}{$\mathrm{T}_{11.5 \text { days }}$} \\
\hline & \multicolumn{6}{|c|}{ Cloprostenol Dose } \\
\hline & First & Second & First & Second & First & Second \\
\hline Plasma progesterone concentration (ng/mL) & $12.5 \pm 10.3$ & $12.2 \pm 6.4$ & $11.9 \pm 8.1$ & $13.8 \pm 3.0$ & $8.7 \pm 9.5$ & $14.8 \pm 5.2$ \\
\hline Diameter of largest follicle (mm) & $6.0 \pm 0.7$ & $5.0 \pm 1.8$ & $4.9 \pm 1.0$ & $5.6 \pm 1.7$ & $5.0 \pm 0.7$ & $5.4 \pm 2.0$ \\
\hline Diameter of second largest follicle (mm) & $5.7 \pm 0.6^{\mathrm{a}}$ & $4.7 \pm 1.4$ & $4.6 \pm 0.9^{b}$ & $4.7 \pm 1.0$ & $4.8 \pm 0.6^{\mathrm{b}}$ & $5.2 \pm 1.4$ \\
\hline Estrus response (\%) & $73.7 .0(14 / 19)$ & $94.7(18 / 19)$ & $77.8(14 / 18)$ & $88.9(16 / 18)$ & $58.8(10 / 17)$ & $88.2(15 / 17)$ \\
\hline Interval to estrus (h) & $53.8 \pm 15.4$ & $43.8 \pm 10.7^{b}$ & $54.3 \pm 9.3$ & $50.6 \pm 13.7^{\mathrm{a}}$ & $45.5 \pm 27.6$ & $47.3 \pm 5.8^{\mathrm{ab}}$ \\
\hline Estrus duration (h) & $24.5 \pm 9.8$ & $27.0 \pm 12.1$ & $29.2 \pm 16.0$ & $22.3 \pm 10.4$ & $33.5 \pm 19.4$ & $23.7 \pm 11.8$ \\
\hline
\end{tabular}

\footnotetext{
${ }^{\mathrm{a}, \mathrm{b}}$ Means with different superscripts within rows differed (Tukey; $\mathrm{P}<0.05$ ). Means without superscripts did not differ $(\mathrm{P}>0.05$ ).
} 


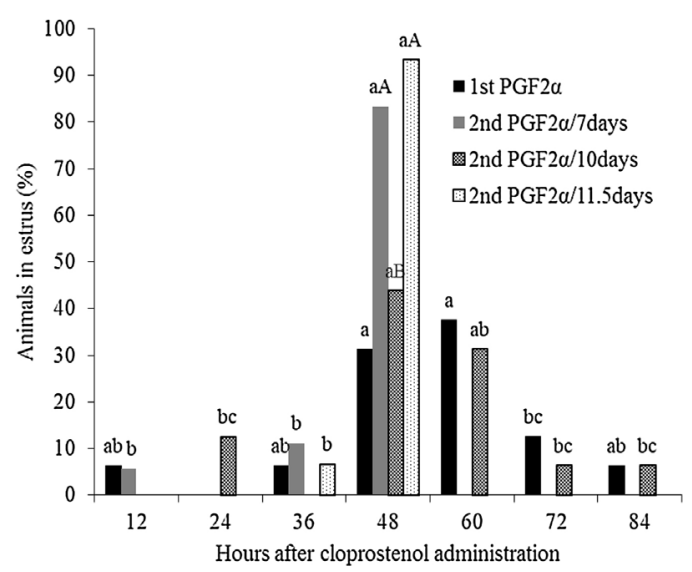

Fig. 1. Percentage (\%) of goats according to interval to estrus onset after hormonal synchronization with two doses of $30 \mu \mathrm{d}$-cloprostenol (PGF2 $\alpha$ ) at intervals of 7 , 10, and 11.5 days after the first $\left(\mathrm{T}_{7}+\mathrm{T}_{10}+\mathrm{T}_{11.5}\right)$ and second $\left(\mathrm{T}_{7}, \mathrm{~T}_{10}\right.$ or $\left.\mathrm{T}_{11.5}\right)$ injection., ${ }^{\mathrm{a}, \mathrm{c}}$ Different superscripts indicate difference by Fisher's exact test along the hours after PGF2 $\alpha$ administration in the same group $(\mathrm{P}<0.05){ }^{\mathrm{A}, \mathrm{B}}$ Different superscripts indicate the difference by Fisher's exact test at $48 \mathrm{~h}$ after $\mathrm{PGF} 2 \alpha$ administration among groups $(\mathrm{P}<0.05)$.

distribution of onset of estrus after both injections are shown in Fig. 1. At $12 \mathrm{~h}$ after the first and second doses of d-cloprostenol, one goat from $\mathrm{T}_{11.5}$ and one from $\mathrm{T}_{7}$, respectively, have demonstrated estrus. At estrus detection performed after the first d-cloprostenol dose in females from $\mathrm{T}_{11.5}$ and $\mathrm{T}_{10}$ goats, two goats from $\mathrm{T}_{7}$ showed estrus spontaneously. This fact occurred at 65 and $41 \mathrm{~h}$ before the d-cloprostenol administration for $\mathrm{T}_{7}$ goats, approximately three and two days, respectively, before first d-cloprostenol administration to $\mathrm{T}_{7}$ goats. Plasma progesterone concentrations obtained for these animals (at the moment of the first dose of cloprostenol) were $2.53 \mathrm{ng} / \mathrm{mL}$ and $1.34 \mathrm{ng} / \mathrm{mL}$, respectively.

The highest concentration of estrus onset was in the period of $48-60 \mathrm{~h}$, either after the first d-cloprostenol (68.8\%) or second $\left(\mathrm{T}_{7}\right.$ : $83.3 \% ; \mathrm{T}_{10}: 75.0 \%$ ) d-cloprostenol injection. A total of $93.3 \%$ of goats treated by $\mathrm{T}_{11.5}$ protocol were in estrus in the same day, accounting for $26.7 \%$ at $36 \mathrm{~h}$ and $66.7 \%$ at $48 \mathrm{~h}$ after the administration of the second dose of d-cloprostenol.

Considering the second dose of d-cloprostenol, the moment of estrus onset is shown in Fig. 2. In goats from T7 protocol, 83.3\% of goats were detected in estrus in the morning compared to $1.7 \%$ detected in the afternoon $(\mathrm{P}<0.05)$. No differences were found in $\mathrm{T}_{10}$ and $\mathrm{T}_{11.5}$ females regarding the period of time (day and night).

When considering the number of nights after which estrus was detected, the majority of goats required two nights to start estrus $(\mathrm{P}<0.05)$ (Fig. 3).

The conception rates were similar $(\mathrm{P}>0.05)$ for $\mathrm{T}_{7^{-}}(55.6 \%-10 / 18)$ than $\mathrm{T}_{10^{-}}(18.8 \%-3 / 16)$ and $\mathrm{T}_{11.5^{-}}(26.7 \%-4 / 15)$ treated goats.

\subsection{Trial 2}

The results of Trial 2 are shown in Table 2. Reproductive parameters were similar $(\mathrm{P}>0.05)$ between breeds. There was no significant interaction between breeds and treatments $(\mathrm{P}>0.05)$. The goats from $\mathrm{T}_{11.5}$ started estrus (49.2 \pm 8.9$)$ later and $(\mathrm{P}<0.05)$ were inseminated earlier in relation to the estrus onset than $\mathrm{T}_{7}(43.1 \pm 6.0)$ goats. From goats displaying estrus, $59.3 \%$

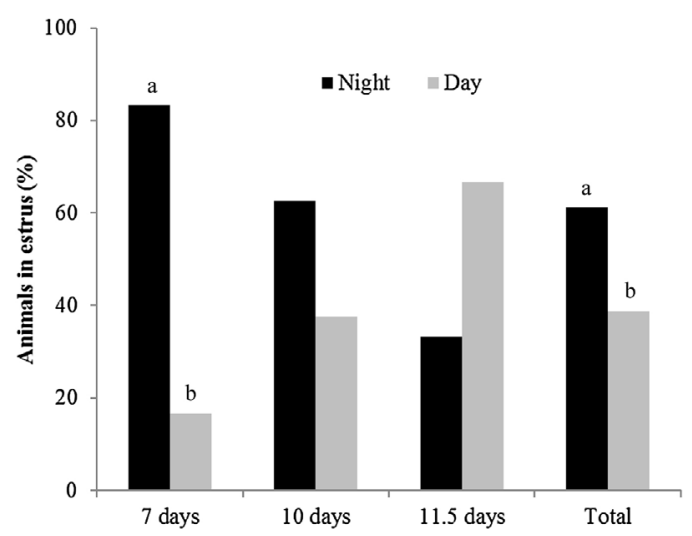

Fig. 2. Percentage (\%) of estrus onset in cyclic Saanen goats after the second dose of $30 \mu \mathrm{g}$ d-cloprostenol at intervals of 7 , 10 , and 11.5 days apart. Night means that estrus was first detected in the morning (estrus onset during the night) and day means that estrus was first detected at the end of the afternoon (estrus onset during the day). ${ }^{\mathrm{a}, \mathrm{b}}$ Different letters, in the same group or total, indicate the difference by Fisher's exact test $(\mathrm{P}<0.05)$. 


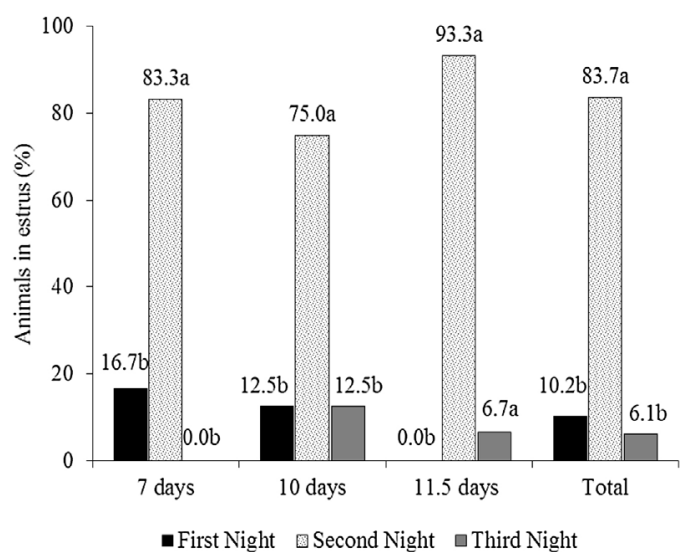

Fig. 3. Number of nights required to estrus onset in cyclic Saanen goats after the second dose of $30 \mu \mathrm{d}$-cloprostenol in intervals of 7,10 and 11.5 days apart., Numbers with different letters in the same group or total differed (Fisher's exact test; $\mathrm{P}<0.05$ ).

(16/27) of $\mathrm{T}_{7}$ and $54.8 \%$ (17/31) started estrus during the night. Only $\mathrm{T}_{11.5}$ goats started estrus at $60 \mathrm{~h}$ after the second cloprostenol administration. These goats were $\mathrm{AI}$ at the end of the afternoon of the same day ( $>10 \mathrm{~h}$ after estrus onset) that they started estrus.

\section{Discussion}

All protocols studied had a satisfactory estrus response after the second d-cloprostenol administration and can be considered in timed AI (TAI) due to a greater concentration of animals in estrus between 48 to $60 \mathrm{~h}$ after estrus onset. Considering the time preconized to AI in relation to the estrus onset (18-24 h) in the present study, these protocols confirm that technicians can perform AI during two to three turns per goat station (afternoon/morning/afternoon). This reduced time is relevant when planning a strategy of AI schemes in conditions similar to those in which this study was done. In addition, goats that showed estrus earlier or later can be subjected to natural mounting. Thus, the overall pregnancy rate per group of exposed females can be expected to be superior as a result of $\mathrm{AI}$ and natural mounting in the same cycle or group of females synchronized.

Precocious estrus onset observed in goats in the present study (12 h after d-cloprostenol injection) can be associated with a possible pro-estrus phase of the estrus cycle at the time of d-cloprostenol administration. It was not evoked by exogenous PGF2 $\alpha$, but they were resultant of a natural estrus in course. Specially in the second cloprostenol administration, this fate can be associated with short estrus cycles. This type of estrus can be more deleterious to a $\mathrm{T}_{10}$ protocol, as shown earlier (Fonseca et al., 2012), because animals can show estrus before the second PGF2 $\alpha$ administration and those goats can have younger CL irresponsive to the effects of exogenous PGF2 $\alpha$ administration. In both cases, these goats will not be naturally mated or AI after the second PGF2 $\alpha$ administration, decreasing the estrus response in the $\mathrm{T}_{10}$ protocol. On the other hand, these goats can show estrus during the expected time after the second PGF2 $\alpha$ administration in the $\mathrm{T}_{7}$ protocol or can have enough time for the CL to be responsive to exogenous PGF2 $\alpha$ administered in the $\mathrm{T}_{11.5}$ protocol. It confirms the hypothesis that the most used protocol of estrus synchronization in goats (10 days apart interval) is the less indicated.

Estrus response after the second dose of d-cloprostenol was similar among treatments, but the dispersion among them was different. For instance, the interval to estrus was lower in the $\mathrm{T}_{7}$-treated goats than goats that received other treatments in both trials.

Table 2

Reproductive parameters of cyclic dairy goats after estrus synchronization with two injections of d-cloprostenol at 7 and 11.5 days apart (Mean \pm SD) and artificially inseminated (AI) according to the time of estrus onset of females.

\begin{tabular}{|c|c|c|c|}
\hline \multirow[t]{2}{*}{ Parameter } & \multicolumn{3}{|c|}{ Interval of cloprostenol administration } \\
\hline & 7 days & 11.5 days & Total \\
\hline Number of animals (n) & 30 & 32 & 62 \\
\hline \multicolumn{4}{|l|}{ Estrus response (\%) } \\
\hline At $36 \mathrm{~h}$ after second cloprostenol dose & $40.7(11 / 27)$ & $22.6(7 / 31)$ & $31.0(18 / 58)$ \\
\hline At $48 \mathrm{~h}$ after second cloprostenol dose & $59.3(16 / 27)$ & $45.2(14 / 31)$ & $51.7(30 / 58)$ \\
\hline At $60 \mathrm{~h}$ after second cloprostenol dose & $0.0(0 / 27)$ & $32.2(10 / 31)$ & $17.2(10 / 58)$ \\
\hline Total & $90.0(27 / 30)$ & $96.9(31 / 32)$ & $93.5(58 / 62)$ \\
\hline Interval to estrus (h) & $43.1 \pm 6.0^{\mathrm{a}}$ & $49.2 \pm 8.9^{b}$ & $46.3 \pm 8.2$ \\
\hline Interval from estrus onset to $\mathrm{AI}(\mathrm{h})$ & $25.0 \pm 2.0^{\mathrm{a}}$ & $16.6 \pm 6.2^{\mathrm{b}}$ & $20.5 \pm 6.3$ \\
\hline Hydrometra (\%) & $7.4(2 / 27)$ & $3.2(1 / 31)$ & $5.2(3 / 58)$ \\
\hline Conception rate $(\%)$ & $85.2(23 / 27)$ & $93.6(29 / 31)$ & $89.6(52 / 58)$ \\
\hline
\end{tabular}

\footnotetext{
${ }^{\mathrm{a}, \mathrm{b}}$ Means with different superscripts within rows differed (Tukey, $\mathrm{P}<0.01$ ); () Number of animals. Means without superscripts did not differ (P $>0.05$ ).

* AI was performed after $10 \mathrm{~h}, 18 \mathrm{~h}$ and $24 \mathrm{~h}$ for goats showing estrous onset at $60 \mathrm{~h}, 48 \mathrm{~h}$ and $24 \mathrm{~h}$ after the d-cloprostenol second dose, respectively.
} 
Although the follicular diameter of goats was similar, it is possible that the largest follicles from $\mathrm{T}_{7}$ goats at the second d-cloprostenol dose were in a growth phase (first follicular wave after first cloprostenol dose). As negative influence of progesterone on their growth was erased by d-cloprostenol administration these follicles could complete their development. The growth follicular rate in goats is near to of $1 \mathrm{~mm}$ /day (Menchaca et al., 2007). It means that for $\mathrm{T}_{7}$ goats, follicles could reach the ovulatory diameter (Esteves et al., 2013) and adequate estradiol production in three to four days after second d-cloprostenol injection. Goats from $T_{10}$ and $T_{11.5}$ were more likely in a regression phase in which smaller follicles could originate ovulatory follicles, indicating more time needed to reach ovulatory diameter and estrus onset. A similar phenomenon was described in estrus synchronized sheep (Menchaca and Rubianes, 2004).

Considering that estrus onset is possibly associated with night events as previously proposed (Fonseca et al., 2005), the protocol of 11.5 days was developed to allow the second PGF2 $\alpha$ to be administered at the end of afternoon. This protocol implied two (48 h) to three $(60 \mathrm{~h})$ nights before starting estrus. This "night event" in association with ovarian follicular status at the moment of cloprostenol administration could explain in part the concentration of estrus associated with this protocol in this period (36-60 $\mathrm{h}$ after the second cloprostenol administration) in $\mathrm{T}_{11.5}$ goats.

In the trials, estrus was initially detected in the $\mathrm{T}_{7}$ and $\mathrm{T}_{10}$ goats in the morning (83.3 and $62.5 \%$, respectively), suggesting that most of the females entered estrus at night. This affirmation is corroborated by previous studies in goats. After monitoring the expression of estrus, Fonseca et al. (2005) reported that $84.8 \%$ of estrus was first identified in the morning (6 am). Fonseca et al. (2008) also noted that $73.8 \%$ of the goats were first observed in estrus in the morning and suggested that in goats, the estrus is predominantly a nightly phenomenon. Likewise, Esteves et al. (2013) observed a 91\% occurrence of night estrus and a $9 \%$ occurrence of day estrus. On the other hand, the 11.5-day protocol evoked estrus predominantly during the day (66.7\% first detected at the end of the afternoon) in first trial and in the night (54.8\%) in second trial. The reasons for this occurrence need to be confirmed, but can also be associated with the two nights warranted before the first estrus onset.

In the current study, at $60 \mathrm{~h}$ after the second d-cloprostenol dose, the estrus behavior was detected in $93.9 \%$ of Trial 1 goats. Menchaca et al. (2004) obtained 78.8\% of ewes in estrus between 25 and $48 \mathrm{~h}$ after the second dose of PGF2 $\alpha$ with a 7-day interval in ewes. It is noteworthy that in the present study estrus behavior was first identified in the same shift (morning or afternoon) in which the second dose of d-cloprostenol was administered for $\mathrm{T}_{7}$ and $\mathrm{T}_{10}$ goats in both trials, and in $\mathrm{T}_{11.5}$ goats in Trial 1 but not in Trial 2 . This fact may suggest that the time of the second administration of cloprostenol (morning or afternoon) could influence the occurrence of estrus onset.

All females presented progesterone concentrations $>1.0 \mathrm{ng} / \mathrm{mL}$, either at the first or the second dose of d-cloprostenol. However, despite the found values of progesterone, some females did not show estrus after synchronization protocols. Values above $1 \mathrm{ng} / \mathrm{mL}$ from day 1 to day 5 have been reported in goats presenting four $(4.1 \pm 0.7 \mathrm{ng} / \mathrm{mL})$ and three $(2.2 \pm 1.1 \mathrm{ng} / \mathrm{mL})$ follicular waves (Menchaca and Rubianes, 2002). However, until the third day of formation, the CL is refractory to the action of prostaglandins (Rubianes et al., 2003). Thus, it can be speculated that, although the progesterone values were found, goats that did not show estrus were possibly at the beginning of the luteal phase. Supporting this argument, at estrus detection performed after the first dose of cloprostenol in females from $\mathrm{T}_{11.5}$ and $\mathrm{T}_{10}$ groups, two goats from the $\mathrm{T}_{7}$ treatment group showed estrus spontaneously. Possibly, this estrus was elicited by the female-female effect (Rodríguez-Martínez et al., 2013) in function of the contact with goats in estrus from the $\mathrm{T}_{10}$ and $\mathrm{T}_{11.5}$ groups. This fact occurred at 41 and $65 \mathrm{~h}$ before cloprostenol administration for $\mathrm{T}_{7}$ goats. Thus, approximately three and two days after estrus detection, progesterone concentrations obtained for these animals (at the moment of first dose of $\mathrm{d}$ cloprostenol) were $2.53 \mathrm{ng} / \mathrm{mL}$ and $1.34 \mathrm{ng} / \mathrm{mL}$, respectively. Despite being above $1.0 \mathrm{ng} / \mathrm{mL}$ (active CL), these females did not return to estrus within the subsequent days after the first cloprostenol application. As discussed earlier, this fact reinforces the hypothesis that younger active CL is not responsive to exogenous PGF2 $\alpha$.

Another fact that should be taken into consideration in relation to goats in luteal phase but not entering estrus after cloprostenol administration is the possible occurrence of a silent heat or even the sexual inexperience of some goats. It has been demonstrated that nulliparous females present high levels of stress that may influence estrus behavior (Gelez et al., 2004). Although it has not been studied, it is possible that stressed or subordinated goats externalize estrus behavior later than less-stressed or dominant ones. On the other hand, previous study showed a negative correlation between the interval to estrus after sponge removal and the respective estrus duration (Fonseca et al., 2008), as shown in the present study. This is supported by the fact that the interval to ovulation was reported as being less variable and also negatively correlated with the duration of estrus (Fonseca et al., 2012) in estrus synchronized goats, a possible indication that goats displaying earlier or later estrus onset after exogenous stimuli were in similar ovarian follicular statuses.

In Trial 1, the conception rate of $\mathrm{T}_{7}(55.6 \% ; 10 / 18), \mathrm{T}_{10}(25.0 \% ; 4 / 16)$ and $\mathrm{T}_{11.5}(33.3 \% ; 5 / 15)$ goats did not differ. Siqueira et al. (2009) using refrigerated semen stored for $12 \mathrm{~h}$ at $5{ }^{\circ} \mathrm{C}$ reported $55.7 \%$ after a single AI performed $12 \mathrm{~h}$ after the estrous onset in Toggenburg goats. Likewise, Esteves et al. (2013) observed a pregnancy rate of 55\% (6/11) in the group treated with human chorionic gonadotropin (hCG) with AI performed $16 \mathrm{~h}$ after estrus onset.

It is known that conception rates are related to time of AI. In Trial 1, there was a negative correlation between the interval to estrus and the duration of estrus. This confirms results of previous studies in estrus induced goats (Fonseca et al., 2005, 2008). A negative correlation $(\mathrm{r}=-0.57)$ between the interval to estrus and the interval to ovulation was reported in estrus synchronized goats with similar $\mathrm{T}_{10}$ protocol (Fonseca et al., 2012). Thus, considering that AI was performed on average at 24 after estrus onset, $\mathrm{T}_{7}$ goats were inseminated before the end of estrus and possibly before the ovulation that occurs near the end of estrus (Fonseca et al., 2012). On average, the other $\mathrm{T}_{10}$ and $\mathrm{T}_{11.5}$ goats were inseminated after estrus and ovulation had ended. AI performed after ovulation was associated with an increased percentage of fair embryos, both in cattle (Saacke et al., 2000) and goats (Vallet and Baril, 1990), and lower pregnancy rates in goats (Motlomelo et al., 2002; Fonseca et al., 2012). 
Based on the results of Trial $1, \mathrm{~T}_{7}$ and $\mathrm{T}_{11.5}$ were tested again in Trial 2 with adjustments according to the interval from the onset of estrus to AI also considering interval to estrus from second d-cloprostenol administration. Again, the interval to estrus was shorter in $\mathrm{T}_{7}$ than in $\mathrm{T}_{11.5}$ goats $(\mathrm{P}<0.01$ ), confirming the results from Trial 1 . However, as discussed above, AI was adjusted to be performed earlier in goats displaying estrus later. Overall, the efficiency of both $\mathrm{T}_{7}$ and $\mathrm{T}_{11.5}$ protocols to assure greater synchronized estrus and the adjustment in AI time in relation to the interval to estrus culminated in elevated conception rates.

Finally, hydrometra was diagnosed in three of the inseminated goats. In these goats in particular, pregnancy checking was done in August (local non-breeding season). Because these goats did not show estrus from AI to pregnancy diagnosis, it was possible that embryo/fetal loss could have occurred at a time in which natural luteolysis could not be evoked. The persistence of these CL assured progesterone permanent status that culminated in hydrometra as previously proposed (Brice et al., 2003). Precocious detection of pregnancy (up to 30 days) was possible and efficient. However, considering the possibility of goats lost their fetuses and also come into pseudo-pregnant status, 60 days checking appears to be more indicated.

\section{Conclusions}

In conclusion, under the current experimental conditions, dairy goats had estrus efficiently synchronized after the use of two doses of d-cloprostenol with intervals of administration of 7, 10, and 11.5 days. The intervals of 7 and 11.5 days promoted a high estrus onset synchrony of goats after the second d-cloprostenol dose. By adjusting the strategy of AI time according to the interval to estrus, more than $90 \%$ of goats can be inseminated at $24 \mathrm{~h}$ intervals, resulting in conception rates near to $90 \%$. Considering these two main results, it is suggested that 7- and 11.5-day intervals of d-cloprostenol administration can be considered as a highly efficient method (high synchronization, estrus response and conception rate), with a lower relative cost (no use of progestagen or gonadotropins), little animal handling (interventions and hormonal administration), and protocols to support AI program during the breeding season in dairy goats.

\section{Conflict of interest}

The authors declare that they have no conflict of interest.

\section{Acknowledgments}

This study was supported by the National Council for Scientific and Technological Development (CNPq; Projects 310166/2012-8 and 479826 2013-7), Fundação de Amparo à Pesquisa de Minas Gerais (Fapemig; Project CVZ-PPM 00042-14) and EMBRAPA (Project 02.08.02.005.00.04). The authors also wish to thank CAPRIMA (Associação de Criadores de cabras Leiteiras da Zona da Mata - MG) for providing animals and animal housing conditions. FZB, MEFO, and JFF are fellows of the CNPq and JMGSF of CAPES.

\section{References}

Baril, G., Remy, B., Leboeuf, B., Beckers, J.F., Saumande, J., 1996. Synchronization of estrus in goats: the relationship between eCG binding in plasma: time of occurrence of estrus and fertility following artificial insemination. Theriogenology 45, 1553-1559.

Brice, G., Broqua, C., Leboeuf, B., 2003. La pseudogestation chez la chèvre laitière [Pseudopregnancy in dairy goats]. Point Vét. 34, 50-52.

Camp, J.C., Wildt, D.E., Howard, P.K., Stuart, L.D., Chakraborty, P.K., 1983. Ovarian activity during normal and abnormal length estrous cycles in the goat. Biol. Reprod. 28, 673-681.

Chemineau, P., Pellicer-Rubio, M.T., Lassoued, N., Khaldi, G., Monniaux, D., 2006. Male-induced short oestrous and ovarian cycles in sheep and goats: a working hypothesis. Reprod. Nutr. Dev. 46, 417-429.

Detweiler, G., Gipson, T., Merkel, R., Goetsch, A., Sahlu, T., 2008. Body condition scores in goats. Annual Goat Field Day, vol. 23. Langston University, Langston, pp. $127-133$.

Esteves, L.V., Brandão, F.Z., Cruz, R.C., Souza, J.M.G., Oba, E., Facó, O., Fonseca, J.F., 2013. Reproductive parameters of dairy goats submitted to estrus synchronization with prostaglandin F2 $\alpha$ associated or not to hCG at estrous onset. Arq. Bras. Med. Vet. Zootec. 65, $1585-1592$.

Fonseca, J.F., Bruschi, J.H., Santos, I.C.C., Viana, J.H.M., Magalhães, A.C.M., 2005. Induction of estrus in non-lactating dairy goats with different estrous synchrony protocols. Anim. Reprod. Sci. 85, 117-124.

Fonseca, J.F., Torres, C.A., Santos, A.D.F., Maffili, V.V., Amorim, L.S., Moraes, E.A., 2008. Progesterone and behavioral features when estrous is induced in Alpine goats. Anim. Reprod. Sci. 103, 366-373.

Fonseca, J.F., Alvim, G.P., Lobo, A.M.B.O., Facó, O., 2011. Técnica Embrapa de inseminação Artificial transcervical em caprinos por meio de fixação cervical. Circular Técnica Número 43. Embrapa Caprinos e Ovinos.

Fonseca, J.F., Maffili, V.V., Santos, A.D.F., Fürst, R., Prosperi, C.P., Rovay, H., Souza, J.M.G., Torres, C.A.A., 2012. Effects of prostaglandin administration 10 days apart on reproductive parameters of cyclic dairy nulliparous goats. Arq. Bras. Med. Vet. Zootec. 64, 349-358.

Gelez, H., Archer, E., Chesneau, D., Campan, R., Fabre-Nys, C., 2004. Importance of learning in the response of ewes to male odor. Chem. Sens. 29, 555-563.

Holtz, W., Sohnrey, B., Gerland, M., Driancourt, M.A., 2008. Ovsynch synchronization and fixed-time insemination in goats. Theriogenology 69, 785-792.

Menchaca, A., Rubianes, E., 2002. Relation between progesterone concentrations during the early luteal phase and follicular dynamics in goats. Theriogenology 57, $1411-1419$.

Menchaca, A., Rubianes, E., 2004. New treatments associated with timed artificial insemination in small ruminants. Reprod. Fertil. Dev. 16, $403-413$.

Menchaca, A., Miller, V., Gil, J., Pinczak, A., Laca, M., Rubianes, E., 2004. Prostaglandin F2 $\alpha$ treatment associated with time artificial insemination in ewes. Reprod. Dom. Anim. 39, 352-355.

Menchaca, A., Miller, V., Salveraglio, V., Rubianes, E., 2007. Endocrine, luteal and follicular responses after the use of the short-term protocol to synchronize ovulation in goats. Anim. Reprod. Sci. 102, 76-87.

Motlomelo, K.C., Greyling, J.P.C., Schwalbach, L.M.J., 2002. Synchronization of oestrus in goats: the use of different progestagen treatments. Small Rumin. Res. 45, 45-49.

National Research Council—NRC, 2007. Nutrient Requirements of Goats. Ed. Natl. Acad. Science, Washington, DC.

Penna, B., Libonati, H., Director, A., Sarzedas, A.C., Martins, G., Brandão, F.Z., Fonseca, J.F., Lilenbaum, W., 2013. Progestin-impregnated intravaginal sponges for 
estrus induction and synchronization influences on goats vaginal flora and antimicrobial susceptibility. Anim. Reprod. Sci. 142, 71-74.

Ribeiro Júnior, I., 2001. Análises estatísticas no SAEG. Editora UFV, Viçosa, pp. 301.

Rodríguez-Martínez, R., Ángel-García, O., Guillén-Muñoz, J.M., Robles-Trillo, P.A., Santiago-Miramontes, M.A., Meza-Herrera, C.A., Mellado, M., Véliz, F.G., 2013. Estrus induction in anestrous mixed-breed goats using the female-to-female effect. Trop. Anim. Health Prod. 45, 911-915.

Rubianes, E., Menchaca, A., Carbajal, C., 2003. Response of the 1-5 day-aged ovine corpus luteum to prostaglandin F2 $\alpha$. Anim. Reprod. Sci. 78, 47-55.

Saacke, R.G., Dalton, J.C., Nadir, S., Nebel, R.L., Bame, J.H., 2000. Relationship of seminal traits and insemination time to fertilization rate and embryo quality. Anim. Reprod. Sci. 60-61, 663-677.

Santiago Moreno, J., Acosta Rodríguez, M., González De Bulnes, A., Castrillo Zubiria, I., Pérez Marín, C., López Sebastián, A., 1999. Evaluation of the small ruminant cystic ovarian disease using transrectal ultrasonography. Arch. Zootec. 48, 157-165.

Siqueira, A.P., Fonseca, J.F., Silva Filho, J.M., Bruschi, J.H., Viana, J.H.M., Palhares, M.S., Bruschi, M.C.M., Peixoto, M.P., 2009. Parâmetros reprodutivos de cabras Toggenburg inseminadas com sêmen resfriado, após diluição em meio à base de gema de ovo. Arq. Bras. Med. Vet. Zootec. 61, $299-305$.

Vallet, J.C., Baril, G., 1990. Effect of time of laparoscopic intrauterine insemination in superovulated dairy goats. In: Lyon. Proc. 6th Scientific Meeting of European Embryo Transfer Association, vol. 1 p. 18.

Vázquez, M.I., Blanch, M.S., Alanis, G.A., Chaves, M.A., González-Bulnes, A., 2010. Effects of treatment with a prostaglandin analogue on developmental dynamics and functionality of induced corpora lutea in goats. Anim. Reprod. Sci. 118, 42-47. 